\section{Percutaneous Endoscopic Gastrostomy Using the Kleinsasser Direct Laryngoscope}

Undernourished patients with head and neck cancer require nutritional support, and the method of choice is enteral feeding. For a number of reasons, endoscopically guided creation of a gastrostomy is preferred. However, placement of a percutaneous endoscopic gastrostomy (PEG) is frequently unsuccessful in these patients (1). Causes of failure include difficulties in opening the mouth, and stenosis of the upper gastrointestinal tract. In cases in which the oral route is not possible, transnasal placement can be carried out (2), or in special situations endoscopic alternatives such as a transmaxillary route (3) can be used. PEGs can be placed during the preoperative or postoperative period, or in conjunction with tumor resection, tracheotomy, or other surgical techniques (4). This prevents crowding of patients, and means that the number of procedurerelated days in hospital can be reduced.

However, the supine position, tracheal intubation, and tumor stenosis (even after laser treatment) can make insertion of the gastroscope into the esophagus particularly difficult. In such situations, we have successfully used the following technique. The pharynx is exposed and straightened with the help of a Kleinsasser-type direct laryngoscope. After this, the endoscope is passed through the laryngoscope into the esophagus (Figure 1). An upper gastrointestinal tract endoscopy is carried out, and a PEG is inserted (Figure 2).

From July 1995 through September 1997, we placed 91 PEGs in patients with head and neck cancer. In 35 cases, the procedure was carried out during intratracheal narcosis in conjunction with tumor resection. In four cases $(11 \%)$, we used the technique described above. The pull-through technique was used. No procedure-related complications occurred. Using this technical modification (transnasal and placement through the direct laryngoscope), we were able to place a PEG in all of these patients.

A. Taller', E. Horváth ${ }^{2}$, L. Harsányi ${ }^{3}$,

J. Élö ${ }^{2}$. L. Iliàs'

${ }^{1}$ Second Dept. of Internal Medicine

${ }^{2}$ Dept. of Head and Neck Surgery,

Uzsoki Municipal Hospital,

Budapest, Hungary

${ }^{3}$ First Dept. of Surgery,

Semmelweis University Medical School, Budapest, Hungary

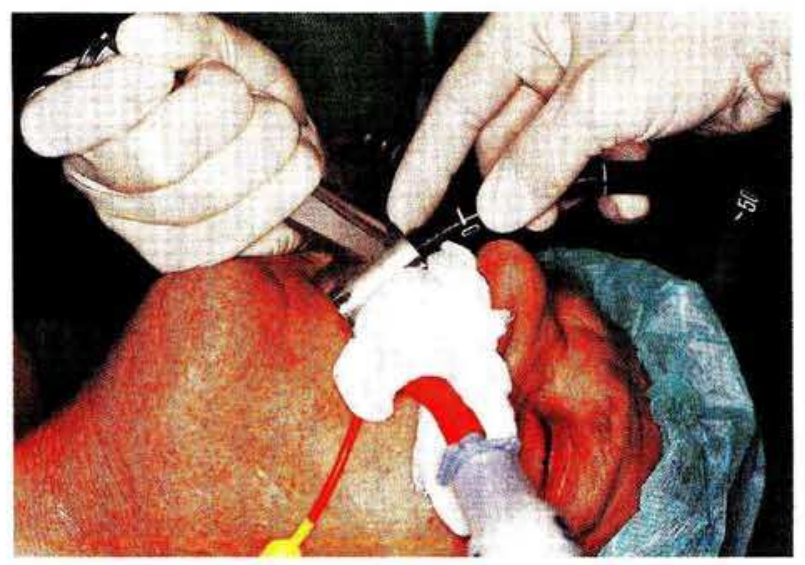

Figure 1: The endoscope being introduced into the upper gastrointestinal tract through a Kleinsasse direct laryngoscope.

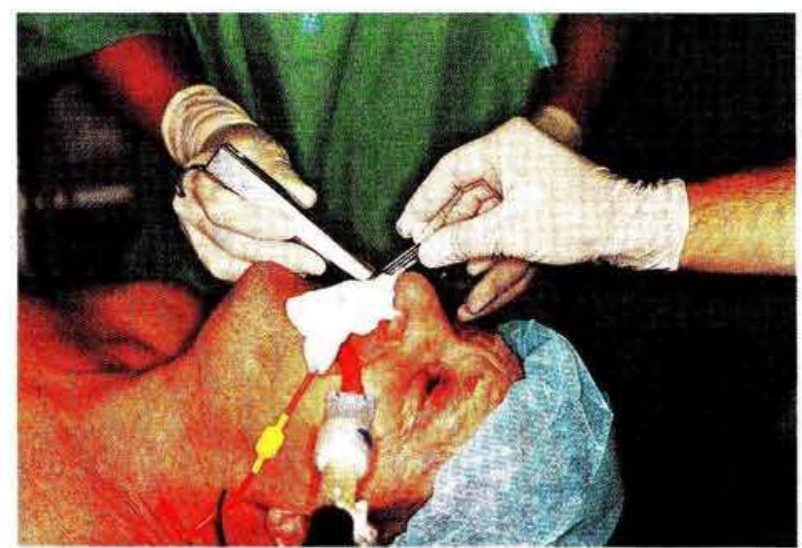

Figure 2: The gastrostomy tube being placed through the direct laryngoscope, using the pull-through technique

\section{References}

1. Hunter JG, Lauretano L, Shiletto PC. Percutaneous endoscopic gastrostomy in head and neck cancer patients. Ann Surg 1989; 210: 42-6.

2. Taller A, Horváth E, Harsányi L, Balatoni Zs, Mliás L. Transnasal percutaneous endoscopic gastrostomy. Endoscopy 1997; 29: 337 .

3. Grier JF, Goldman DE, Gholson CE. Transmaxillary percutaneous endoscopic gastrostomy. Gastrointest Endosc 1994; 40: 778-9.
4. Selz PA, Santos PM. Percutaneous endoscopic gastrostomy: a useful tool for the otolaryngologist/head and neck surgeon. Arch Otolaryngol Head Neck Surg 1995; 121: 1249-52.

Corresponding Author

A. Taller, M.D

Second Dept. of Internal Medicine

Uzsoki Municipal Hospital

Uzsoki utca 29

1145 Budapest, Hungary

Fax: + 36-1-2514060 